\title{
How to be popular
}

\author{
Increasingly, scientists are expected to go beyond the traditional scientific paper to explain their research \\ to a non-specialist readership. We offer some tips on writing popular science for a general audience.
}

As the budgets of governments worldwide become ever tighter, it is more important than ever for scientists to be able to explain - and in some sense justify their research to a wider audience. Yet few have received formal training in writing at all, let alone in popular writing. There are many forms such writing can take: press releases, perspective pieces for magazines, or even blogs. In Nature Physics, although we strive to ensure that everything we publish is as accessible as possible, this is of utmost importance in our News and Views section, for which we commission practising scientists to write about research that is published in Nature Physics or elsewhere in the scientific literature. On the whole, physicists do a pretty good job of explaining these advances to colleagues in other fields. Yet there are a number of aspects of popular writing that our writers find challenging. We'll describe the most common pitfalls.

For a writer, the most important person in the Universe is the reader. And the most important thing to know about the reader is that you are subject to his or her whim. Every sentence you write must maintain the reader's interest, grip them and keep them reading to the end. As veteran reporter Tim Radford points out in his widely circulated journalists' manifesto (http://go.nature.com/JGVCyi), "This is because, although you - an employee, an apostle or an apologist may feel compelled to write, nobody has ever felt obliged to read." And given half a chance, they will stop reading what you have written and turn the page in an instant.

The most engaging writing tells a story. A good story is a journey, and most people won't follow you on this journey unless you give them some idea of where it's headed. So before you even start, you need to decide where you want it to end. Ask yourself, what is the most surprising or significant aspect of the work you're writing about? When you first heard (or read) about the research, what about it made you think, "Wow, I didn't expect that!" It needn't be what the scientists who conducted the work think is the most important aspect: indeed, for a Nature Physics News and Views, a blog entry or similar, it is your unique perspective that readers (and editors) are interested in.

The structure of the piece should reflect the journey that you've set out to describe. Remember, it needs a beginning, a middle and an end - and, unless you're Quentin Tarantino, it needs to be presented in this order. The first paragraph is the most important of the piece. It sets the stage, addressing the cardinal questions: what, why, who and how. It introduces, briefly, the wider context and motivation for the research and identifies the key challenges it is to address. It doesn't need details - that's what the middle of the piece is for.

\section{Remember, the piece needs}

$$
\begin{aligned}
& \text { a beginning, a middle and } \\
& \text { an end }- \text { and, unless you're } \\
& \text { Quentin Tarantino, it needs to } \\
& \text { be presented in this order. }
\end{aligned}
$$

On any journey, it's tempting to stop at other attractions on the way. For long journeys this can break the monotony, but for short journeys it's usually a distraction. Pick one key idea, one destination, and stick to it. Sometimes in writing you can set out for one place and on the way discover yourself heading towards another - that's fine, and if you discover that the new destination is more exciting than the original, don't be afraid to change your plans. But don't try to include both destinations, unless they're closely neighbouring towns, like Buda and Pest. You only have the time to reach one.

Hype doesn't help, neither do hyperbolic adjectives such as 'very', 'extremely' and 'remarkably'. It's not enough to simply assert that something is exciting, notable, novel or useful explain why. Don't begin any sentence with 'interestingly': it is for the reader to decide whether something is interesting, it's your job to persuade them that it is.
And before you describe anything as ubiquitous, pause and consider: if everyone knows it's ubiquitous - as is usually the case for ubiquitous things - there's probably no point. Cement is ubiquitous; silicon is ubiquitous; organic molecules are ubiquitous; vector calculus is ubiquitous; so what? Analogies, on the other hand, are great. But anthropomorphisms are usually terrible. Silicon doesn't have a few tricks up its sleeve: semiconductors don't perform tricks, neither do they have sleeves.

At the opening of A Brief History of Time, Stephen Hawking notes that his editor warned him that for every equation in the book its readership would be halved, and so he included only a single equation $-E=m c^{2}$. Writing for physicists is less constrained, but not by much. Few physicists are afraid of equations. But most equations - apart from those presented in any undergraduate physics course - represent a short-hand that only specialists appreciate. Consequently, formulae are usually a waste of space, unless the implications of every index and every coefficient is explained in long form. Equations in popular writing are not efficient, they're lazy. It's usually much better to describe in words the key relations that they embody.

And finally, when you've crafted some beautiful prose, be ready for the edit. Unless you're writing for your own personal blog, it's unlikely that every word in your initial draft will make the final cut. In the world of professional journalism, most submissions are edited substantially; even seasoned writers regularly see their copy transformed into something quite different from their original draft. The reason is that an editor is closer to the reader than a writer. Editors set the tone and the scope, and it's the editors' vision that ultimately determines the success of a journal. So if an editor has made a change that you're not happy with, don't just change it back - it's been edited for a reason. Explain why you're not happy with the change, and try to rephrase in way that still chimes with the editor's version. 